\section{O ESPORTE-PUBLICITÁRIO-INTERATIVO E INFÂNCIA NO CONTEXTO DA COPA DO MUNDO DA FIFA 2014}

\author{
INTERACTIVE-ADVERTISING-SPORT AND CHILDHOOD IN THE CONTEXT OF \\ THE 2014 FIFA WORLD CUP
}
EL DEPORTE PUBLICITARIO INTERACTIVO Y LA INFANCIA EN EL CONTEXTO DE LA COPA MUNDIAL DE FÚTBOL FIFA 2014

Mariana Mendonça Lisboa*, Giovani Lorenzi Pires**

Mariana Mendonça Lisboa*, Giovani Lorenzi Pirestu

Publicidade.

Esportes.

Criança.

\section{Palavras chave:}

Keywords:

Advertising.

Sports.

Children.
Palabras clave: Publicidad. Deportes. Niños.
Resumo: $O$ objetivo do estudo é compreender as relações entre publicidade, esporte e infância a partir da articulação de elementos teórico-conceituais fundamentadores do debate, e dialogando com a campanha publicitária "\#Joga pra Mim", da Sadia, veiculada na Copa do Mundo de Futebol - FIFA 2014. Observamos o esporte-publicitário-interativo como uma nova linguagem midiática que explora o conteúdo esportivo na elaboração de narrativas transmídias. As crianças ganham destaque pelo potencial de consumo gerado e por contribuir ao apelo emocional. Predicativos importantes para mídia-educação se erguem para compor reflexões que auxiliam na interpretação da cultura esportiva contemporânea diante das diversas plataformas de mídia e seus interesses comerciais.

\begin{abstract}
This study aims to understand some relations between advertising, sports and childhood by bringing together some theoretical and conceptual elements that are fundamental to the debate in a dialogue with Sadia's advertising campaign "\#Joga pra Mim", broadcast during the World Cup Football - FIFA 2014. We looked into interactive-advertising-sport as a new media language that explores the sports content in the preparation of transmedia narratives. Children are highlighted because of the consumption potential they generate and because they contribute to the emotional appeal. Important aspects for media education are raised to build reflections that help to interpret contemporary sports culture on the various digital platforms and their business interests.
\end{abstract}

${ }^{*}$ Rede Municipal de Educação. Florianópolis, SC, Brasil. E-mail: marianaml_floripa@hotmail.com

**Universidade Federal de Santa Catarina. Florianópolis, SC, Brasil. E-mail: giovani.pires@ufsc.br

Recebido em: 24-05-2016 Aprovado em: 05-05-2017 diversas plataformas digitales y sus intereses comerciales. 


\section{REFLEXÕES INICIAIS: PUBLICIDADE E INFÂNCIA EM TEMPOS DE COPA DA FIFA}

O modo predominante de ser/estar na sociedade globalizada representado através das condutas, valores e compreensões em relação ao esporte contribui para instauração do que é chamado de cultura esportiva (PIRES, 2002), cujos significados são simbolicamente incorporados, principalmente, através da mediação feita pela mídia, que tem como um de seus principais clientes os anunciantes. A cultura esportiva apropriada, ressignificada e compartilhada na infância contemporânea, naquilo que Corsaro (2002) chamou de reprodução interpretativa da criança, e que é observado nas vivências e interlocuções com o esporte (LISBOA, 2007), sofre interferências oriundas da realidade social em que as dinâmicas e interesses da publicidade tornam-se presentes.

Acompanhando em detalhes a programação e os conteúdos das diferentes plataformas de mídia, vemos que o esporte - entendido como um fenômeno social e cultural (BRACHT, 1997) - está presente nos mais variados gêneros midiáticos, e não apenas nos programas e espetáculos específicos. Fato este também identificado por crianças escolares, (LISBOA, 2007) que observam o esporte-da-mídia ${ }^{1}$ sendo apropriado/explorado em diversas publicidades e programas televisivos, entre eles: os infantis, noticiários e novelas. 0 esporte, assim, é motivo das mais diferentes informações, entretenimentos e publicidades - tripé sobre o qual se estabelece o discurso midiático (PIRES, 2002) -, sendo suas hibridizações e diluições bastante exploradas, uma vez que se configura como uma moeda/mercadoria de grande valia e interesse midiático.

Explorado em seu potencial econômico, o esporte mobiliza inúmeras estratégias e recursos da publicidade (mola mestra do sistema de mídia, cf. GASTALDO, 2002) para cativar e construir as audiências e os consumidores necessários à mercadorização/ comercialização da cultura esportiva e ao consumo de produtos e serviços ofertados. Na publicização do esporte, entram em jogo modelos emocionais (a promessa de felicidade) e o fetiche da imagem espetacular que, na contramão da racionalidade, busca seduzir e criar necessidades e desejos a serem satisfeitos através do consumo dos produtos da Indústria Cultural (ADORNO; HORKHEIMER, 1985) agora, em sua fase espetacularizada, como afirma Kehl (2004), ao compreender o processo de "espetacularização da sociedade" (DEBORD, 1997)2 não como uma ruptura ou novo paradigma, mas uma consequência e desenvolvimento daquela "indústria", por intermédio da poderosa mídia televisiva. Para Kehl (2004, p. 44), "[...] da indústria cultural à sociedade do espetáculo, o que houve foi um extraordinário aperfeiçoamento técnico dos meios de traduzir a vida em imagem, até que fosse possível abarcar toda a extensão da vida social".

$\mathrm{Na}$ esteira das reconfigurações ampliadas do conceito a partir das transformações e inovações sociais, percebem-se ainda, conforme aponta Jenkis (2009), a integração

10 termo "esporte-da-mídia", utilizado ao longo do texto, significa que a instituição mídia apropria-se e dá sentidos/significados a essa manifestação cultural de acordo com seus interesses, o que lhe confere algumas características peculiares que, resumidamente, e de acordo com Betti (2001), são: 1) Ênfase em um discurso sobre o esporte, ou na "falação esportiva" (ECO, 1984); 2) Monocultura esportiva, expressa na ênfase dada ao futebol; 3) Sobrevalorização da técnica televisiva em relação ao conteúdo; 4) Superficialidade, expressa na cultura do efêmero, do breve e do descontínuo; 5) Prevalência de interesses econômicos, orientados pela mercadorização do esporte frente aos índices de audiência/consumidores.

2 A espetacularização da sociedade é explicitada por Guy Debord (1997) ainda na década de 1960, ao fazer uma análise crítica da moderna sociedade do consumo, em que se verificam fortemente a tirania das imagens e a submissão alienante ao império da mídia. Nesta perspectiva, ocorre uma autonomização das imagens, que passam a ser consumidas como referenciais de identificação do indivíduo reificado, ou seja, as imagens tornam-se um espelho espetacular de sua vida danificada, e uma representação do mundo à sua volta, traduzido sob o espetáculo: "quando o mundo real transforma-se em simples imagens, as simples imagens tornam-se seres reais e motivações eficientes de um comportamento hipnótico" (DEBORD, 1997, p.18). 
progressiva de novos e velhos meios de comunicação, o entrecruzamento da mídia corporativa com a mídia alternativa e a interação imprevisível do poder dos produtores e consumidores, que propiciam e apropriam-se de um fluxo de conteúdo através de múltiplas plataformas midiáticas. Menos que um processo tecnológico de unificação de diferentes funções, a ideia de "cultura da convergência" desenvolvida pelo autor representa uma transformação cultural potencializada pela interação dos sujeitos/consumidores, à medida que são incentivados a buscar novas informações e estabelecer conexões diante dos recursos e das produções de mídia dispersas.

A antiga compreensão de passividade dos espectadores na recepção às produções de mídia também vai sendo modificada, pois as funções monolíticas de produtores e receptores vão dando lugar às possibilidades de interação e participação, propiciadas pelo contexto em que novas regras e dinâmicas são estabelecidas. Destacam-se, entre as novas configurações sociais propiciadas pela ideia de convergência, o surgimento de uma cultura participativa (novos modelos de produção cultural) e a instauração da inteligência coletiva (acesso a novas estruturas sociais). As redes sociais (mas não apenas) seriam importantes mecanismos propulsores dessas dinâmicas em que os receptores agem coletivamente na construção, por exemplo, de comunidades de fãs ${ }^{3}$ que interagem na divulgação, construção e significação de conteúdos diversos, aos moldes das "comunidades interpretativas" (MORLEY, 1980). Esse conceito pode ser ressignificado no contexto de consumo da cultura digital, especialmente pelo surgimento das redes sociais na internet que, como aponta Recuero (2009), são instrumentos transformadores da produção/circulação de conhecimentos e potencializadores de ações colaborativas entre os sujeitos. Desta forma, a interpretação da realidade feita por grupos ou comunidades interpretativas, na vigência da cultura digital e da convergência (JENKIS, 2009), agrega novos elementos de compreensão, como: a comunicação se dá em um espaço virtual público e publicável, com registro digital; a modificação da noção de localidade geográfica nas relações sociais alarga a ideia de comunidade, rompendo barreiras locais; a possibilidade de diálogo e/ou interação entre os atores da comunicação (receptores e emissores originais).

Como um exemplo de entretenimento (publicitário?) da era da convergência digital, Jenkins (2009) apresenta o fenômeno Matrix, que surge em 1999, com o primeiro filme dos irmãos Wachowsky. Ao analisar os diversos produtos midiáticos derivados do filme e suas estratégias de produção e circulação, constata a integração de múltiplos textos na elaboração de uma história tão ampla que extrapola uma única mídia, configurando-se como uma narrativa transmídia. Há grandes motivações econômicas por trás dessas produções, observadas no interesse em integrar entretenimento e marketing/publicidade, e na busca por criar e aprofundar fortes ligações emocionais de marcas/franquias com os consumidores, tendo em vista 0 aumento das vendas, também para ou através das crianças, e 0 alcance de todos os meios de comunicação.

Em períodos de grandes eventos esportivos ficam mais evidentes as diversas apropriações que os meios de comunicações e as publicidades fazem do esporte. Não somente se cria uma atmosfera propícia ao espetáculo esportivo que é "agendado" (FAUSTO NETO, 2002), como também se aproveita dessa popularidade para impulsionar a venda de diversos produtos, marcas e serviços. Muitas mercadorias, inclusive sem relação com a cultura esportiva, através de "estratégias do tipo associativo" (FERRÉS, 1998), almejam

3 Baseada na cultura dos fãs, esta ideia opera à sombra da cultura comercial, sendo também uma reação e uma alternativa a ela, por meio da apropriação e transformação de materiais da cultura de massa. 
agregar valores ao produto, explorando representações positivo-funcionais do esporte, e os atletas como garotos-propaganda de slogans personalizados. Neste contexto as crianças não são ignoradas, pelo contrário, já que se pretende também, desde cedo, criar as audiências necessárias à manutenção do gosto pela assistência midiática dos eventos esportivos, e os consumidores fiéis de marcas, produtos e tecnologias. Antigamente vistas como os "filhos dos clientes", hoje as crianças são consideradas um mercado e segmento autônomo da economia, sendo elas mesmas uma clientela específica de empresas e anunciantes (PEREIRA, 2002).

A Copa do Mundo de Futebol da FIFA, especialmente pelas suas ligações e proximidades com um sentimento positivo da nacionalidade brasileira triunfante, que merece ser comemorada, afinal, somos "os melhores do mundo" (GASTALDO, 2002), é considerada um momento ímpar na cultura de consumo esportivo do Brasil, a partir da hipertrofia do esporteda-mídia, expresso na congregação das maiores audiências midiáticas e da maximização dos lucros e rentabilidades. Grandes empresas e marcas disputam espaço-tempo da publicidade, associando ou promovendo seus produtos com o evento e a modalidade esportiva, vendendo muito mais do que mercadorias, mas, sobretudo, desejos, sonhos e estilos de vida - eficazes modelos emocionais de identificação e integração do público-alvo.

A infância, assim, é ressignificada à luz de uma proeminente cultura de consumo orquestrada, sobretudo, pela publicidade, inclusive esportiva, inserida nas contradições e dinâmicas da realidade social e em meio às transformações culturais decorrentes dos avanços infotecnológicos e dos novos modos de acessar e se relacionar com a mídia. Diante dessa problemática, o texto tem como objetivo compreender as relações entre publicidade, esporte e infância, a partir da articulação de elementos teórico-conceituais fundamentadores do debate, e dialogando com uma campanha publicitária veiculada na ocasião da Copa do Mundo de Futebol - FIFA 2014.

Durante o evento foram observados dois lócus da publicidade televisiva em canais abertos, que são âncoras para outras possibilidades transmidiáticas, a saber: as transmissões dos jogos do Brasil e os programas esportivos de debates. Ao todo identificamos, em uma primeira etapa, 14 anúncios nos intervalos comerciais da TV que atendiam os critérios de inclusão da pesquisa: i) tratar-se de publicidade relacionada à Copa do Mundo da FIFA 2014, produzida pelos patrocinadores oficiais do evento; ii) ser dirigida às crianças (endereçamento) e/ou utilizar, com significativo destaque, a imagem infantil. Em um segundo momento, após acompanhar as possibilidades transmidiáticas das publicidades, sobretudo nos sites institucionais e rede social (Facebook), selecionamos a campanha publicitária "Joga pra Mim", da Sadia, como um exemplo para análise. Consideramos ter sido este o caso mais emblemático do objeto de estudo que versa sobre o entrelaçamento da tríade infância, publicidade e esporte, além de ter sido a campanha que empregou mais estratégias de narrativas transmídias. Desta forma, o corpus da pesquisa foi constituído pela observação e arquivamento digital das produções comerciais da referida campanha publicitária, recolhidas na veiculação da televisão aberta, além do site institucional (internet) e ainda da fanpage da empresa na rede social Facebook, durante a realização do evento.

Entende-se o anúncio publicitário como um gênero narrativo (BAKHTIN, 1997) que utiliza textos, imagens e sons em sua composição e, portanto, pode ser descrito com profundidade a partir do olhar atendo para os elementos e estratégias utilizadas. Assim, por meio do processo descritivo dos anúncios publicitários, elencamos algumas unidades interpretativas, 
como: enunciadores, enredo, papéis dos personagens, recursos audiovisuais e digitais, sons e iconografias, que foram exploradas por meio da análise de conteúdo.

\section{JOGA PARA MIM?! O ESPORTE-PUBLICITÁRIO-INTERATIVO E AS CRIANÇAS}

O esporte propagado pelos meios de comunicação, ao qual se faz referência nesta pesquisa como esporte-da-mídia, não se restringe à cobertura de espetáculos esportivos (jogos), como os campeonatos regionais, nacionais e internacionais das modalidades (com destaque para os grandes eventos esportivos), mas também inclui sua tematização como assunto de pautas jornalísticas ou abordagem em comerciais diversos. Desta forma, o conteúdo esportivo apropriado pela mídia é encontrado no entretenimento dos jogos, nas informações jornalísticas diárias e também nas publicidades, percorrendo todas as instâncias do discurso midiático. Interessa-nos aqui, particularmente, sua abordagem pela publicidade na veiculação/anúncio de produtos de alguma forma relacionados ao esporte, e que é organizada em uma área denominada marketing esportivo, que se constitui a partir das necessidades e dos interesses em transformar o esporte em um produto, campo e processo de venda, a partir de olhares empreendedores e da gestão dos negócios envolvidos. Isto porque se vende diretamente o esporte (esporte como produto), vendem-se produtos relacionados ao seu meio (esporte como campo de vendas) e, ainda, produtos sem relação com o esporte mas que, por meios de estratégias associativas, buscam agregar valores (esporte como processo de venda). Ao explicar o marketing esportivo, Tambuci (2011, p. 671) divide-o em duas vertentes de atuação:

\footnotetext{
Na primeira, as ações de marketing organizam-se ao redor do produto esporte. Na segunda, há uma bifurcação, de um lado, temos ações de marketing que se organizam ao redor de produtos relacionados ao esporte, que não devem ser confundidos com produto esporte. Do outro lado, temos ações de marketing que trabalham produtos não relacionados ao esporte.
}

Verifica-se que existem atuações comerciais diretas e indiretas com o esporte, por meio da aplicação dos princípios e processos de marketing à publicidade dos produtos esportivos e à publicidade de produtos não esportivos, por meio de associações (SHANK, 2002). No contexto da Copa da FIFA - 2014, muitas publicidades tematizavam o evento sem, no entanto, ter uma relação direta do produto/marca com o meio esportivo. Em grande parte, o esporte (futebol) e o evento são utilizados, pelo seu poder simbólico, como representação positiva de valores e estilo de vida que se desejava destacar na marca.

\footnotetext{
O valor simbólico do esporte associado a uma marca ou a um produto lhes confere 0 valor-signo que estabelece a diferença entre elas e seus concorrentes pelo fato de agregar à marca ou ao produto um valor que, na realidade, supera seu valor de uso. [...] Esse tipo de mecanismo se mostra eficaz porque a imagem do esporte é de repercussão excepcional, uma vez que se mantém imolada ao longo da história da humanidade, construindo um imaginário universal de inquestionável credibilidade nas mais diversas culturas. (TAMBUCI, 2011, p. 679).
}

Ao eliminar as contradições, tensões e exclusões presentes no fenômeno esportivo, tomados a partir de sua referência ao esporte de rendimento, por meio daquilo que se chama de "representações positivo-funcionais do esporte", a publicidade constrói uma visão mítica da cultura esportiva, atrelada a uma supervalorização das suas qualidades. Representações do esporte como: "ser campeão", "vencer na vida", "esforço pessoal", "disciplina", presentes 
também nas publicidades, são exemplos de narrativas que alimentam o imaginário social, construindo sentidos/significados da cultura esportiva hegemônica, que servem muito bem aos propósitos emocionais das publicidades.

Para ilustrar e aprofundar o debate sobre as características e estratégias da (nova) publicidade do esporte que tematiza a infância, apresentaremos a campanha publicitária transmidiática desenvolvida pela Sadia durante a Copa da FIFA - 2014, como um exemplo analítico. A Sadia é uma indústria de produtos alimentícios derivados de carnes, além de comercializar massas, margarinas, queijos e sobremesas. Sua campanha publicitária por conta do evento, denominada \#Joga pra Mim, tinha como personagens transmídias as crianças, e o anúncio de TV foi frequentemente veiculado na ocasião do evento, conforme descrito a seguir.

O comercial televisivo da Sadia, de aproximadamente 30 segundos, exibe 20 cenas (tomadas de câmera) em que crianças brancas, algumas de óculos, outras de olhos claros, fazem um pedido, em forma de apelo: "Seleção, esqueça os adultos, é para mim que você tem que jogar. Joga para mim!?". Afinal, como as crianças vão dizer ao longo do anúncio, elas nunca viram o Brasil ganhar um mundial. Uma menina fala que seu pai já viu três títulos, e outro menino complementa que foi a maior festa. $O$ cenário é basicamente composto por crianças nas ruas (tomadas externas) e campos de futebol (local exclusivo dos meninos). A logomarca da Sadia aparece em algumas placas na beira do campo, em letreiros de comércios da cena e no boné de uma criança. Em uma passagem de animação gráfica (estádio de futebol), a mascote da marca, o "Peru da Sadia", também aparece dançando e segurando uma placa com brasão da Confederação Brasileira de Futebol (CBF). A locução (em off) de um adulto afirma que o Brasil já "papou" cinco títulos e a Sadia patrocina a seleção, pois para muita gente este vai ser o primeiro. No meio das imagens e do insistente pedido feito pelas crianças, aparece em destaque na tela o slogan/expressão da campanha, configurada na hashtag \#jogapramim.

Ao entrar no site oficial da empresa, percebemos que o denominado movimento/ campanha \#Joga pra Mim amplia-se e complementa-se, dialogando com "aqueles que já viram o Brasil ganhar uma, duas, três vezes ou nenhuma vez". Desta forma, os conteúdos digitais são estruturados em três sessões de navegação no site, a saber: 1) Chef da Seleção - espaço em que além de apresentar o perfil do vigésimo quarto convocado da seleção, o chef, por meio de um vídeo e história do personagem, também disponibiliza o cardápio dos jogadores e petiscos/comidas do chef, por meio da apresentação das receitas (com vídeos), como a do "enroladinho pé-quente", preparadas com diversos produtos da Sadia; 2) Joga Pra Mim espaço interativo em que é possível gravar e enviar vídeos (mensagens em audiovisual) de apoio para a seleção brasileira, e em que se pode assistir aos vídeos de quem já participou; 3) App Eu Vi - espaço em que é disponibilizado um aplicativo, de conexão com o Facebook, que coloca na foto do perfil da rede social a quantidade de estrelas que o usuário viu o Brasil ganhar. Vários conteúdos disponíveis ofereciam a opção de curtir e compartilhar por meio de links com as redes sociais.

Navegando pela fanpage oficial da empresa no Facebook, logo se visualizou, na página de capa, imagens de crianças de diferentes idades, vestidas com as cores do Brasil, e o slogan da campanha destacado, \#jogapramim. As atualizações de postagem na página são frequentes, misturando mensagens de incentivo, torcida, informações, publicidades, divulgação de vídeos dos consumidores e do comercial televisivo (e suas versões estendida), receitas e 
publicidades de produtos da marca. As publicações oficiais são precedidas de comentários e conteúdos gerados pelos usuários, alguns que, de modo criativo e transgressor, ressignificam a narrativa da campanha produzindo novos significados, por vezes irônicos.

Ficou evidente que as estratégias da publicidade esportiva da Sadia apresentam característica do chamado marketing de 360 graus. Discorrendo sobre algumas novas técnicas de marketing que auxiliam a compreensão das mudanças empreendidas, Buckingham (2012) apresenta o "marketing 360 graus" ou "marketing sinergético" como uma nova modalidade de marketing integrado e de multicanais, propiciado pela convergência e integração das novas e diferentes mídias e tecnologias. Cria-se uma gama sempre crescente de produtos/mercadorias adicionais ao benefício único do produto principal.

Uma pesquisa da Fundação Família Kaiser, de 2006 (GUEDES; COSTA, 2013), sobre a publicidade de alimentos, indicou que $85 \%$ das empresas que anunciam na tevê também estão desenvolvendo formas semelhantes de publicidade na internet; $75 \%$ possuem sites específicos para as crianças; e muitos possuem o endereço eletrônico de seu site na embalagem de seus produtos. Atualmente verifica-se a popularização e divulgação de hashtags (representado pelo símbolo de cerquilha \#) nas campanhas publicitárias, indicando um hiperlink para as redes sociais e digitais, construídos a partir de fusões com palavras-chave ou slogans dos anúncios.

\subsection{Discussão dos "achados" da pesquisa}

Aos moldes do conceito de "narrativas transmidiáticas" de Jenkins (2009), a campanha \#Joga pra Mim buscou ampliar seu campo de atuação, através de um fluxo de conteúdo disponibilizado em múltiplas plataformas midiáticas (TV, site, aplicativos, redes sociais), composto por uma narrativa que atualiza e aprofunda a história esportiva a cada nova/ diferente experiência propiciada ao consumidor. Neste contexto, informação, entretenimento e publicidade se misturam, bem como os papéis entre produtores e consumidores, quando estes assumem a condição de "prosumers", aqueles que também produzem conteúdo, como os vídeos, imagens e postagens/comentários. Prosumers é um termo originado do inglês que provém da junção de producer (produtor) e consumer (consumidor), originalmente cunhado por Alvin Tofler, e atualmente ligado aos participantes da Web 2.0, em que todos podem produzir e consumir simultaneamente (PASSARELLI; JUNQUEIRA, 2012).

As narrativas transmidiáticas do esporte são utilizadas como potencializadoras das estratégias de construir relações afetivas com os consumidores, por meio da oferta de experiências e conteúdos, que misturam o entretenimento e a publicidade, e ainda propiciam a interatividade. Uma gama de produtos, assim, é organizada em torno da história/enredo principal, geralmente associando o esporte ao conceito/identidade da marca, e tendo as crianças como personagens transmídia. Percorrendo diferentes plataformas de mídia, que ampliam a história e oferecem diferentes experiências de consumo, a descrição da campanha da Sadia retrata a perspectiva atual da publicidade, a sua extensão por meio de narrativas transmídias, que exploram o conteúdo esportivo, e as crianças como vínculo emocional positivo e cativo, mesclando-se com a linguagem do entretenimento e possibilitando a interatividade aos consumidores. Castro (2012) destaca que os modelos inovadores surgidos no âmbito da cultura digital oferecem diversas experiências relacionadas à marca, especialmente valendo-se da lógica do entretenimento, estimulando o chamado consumo de experiências. Perspectiva 
que busca mobilizar e captar o público, de atenção fugaz e cliente em potencial, por meio de diferentes plataformas e recursos tecnológicos, propiciando interatividade e diversão enquanto anuncia marcas e produtos.

A narrativa transmídia "Joga pra Mim" desenvolvida pela Sadia percorre diferentes plataformas/recursos de mídia (TV, site, redes sociais, aplicativos) e cada novo texto colabora de maneira particular para o enredo principal. Nos dois anúncios televisivos encontrados, um durante a participação brasileira na competição e o outro após a derrota para a Alemanha, as crianças-propagandas anunciam a ideia da campanha, sem apresentar/vender produtos específicos, mas sim a marca. Buscam criar uma familiarização do tema esportivo com as crianças e adultos, remetendo através dos recursos gráficos (hashtag, slogan, textos) a continuidade e exploração do conteúdo em outras mídias. No universo virtual, a expansão comercial é ampliada através dos diferentes recursos digitais. Vídeos com receitas e produtos são veiculados e compartilhados nas redes sociais (Facebook, YouTube). Aplicativos podem ser baixados para que os consumidores participem da história, socializando suas experiências com a história da campanha comercial, a Copa do Mundo de Futebol - FIFA. Ainda, possibilidades interativas são divulgadas e estimuladas, fazendo circular novos conteúdos produzidos pelos usuários/consumidores que participam da campanha e contribuem para divulgar a marca.

Os achados da pesquisa, no que se referem ao discurso midiático-esportivo, nos levaram a buscar um conceito que melhor explicasse o modelo híbrido e interativo observado nas esferas comunicativas. Neste sentido, Covaleski (2010) cunha a expressão entretenimentopublicitário-interativo, através da qual ele identifica e descreve duas novas funções derivadas das transformações operadas na publicidade no âmbito da cultura digital: entreter e interagir. Assim, além da já observada hibridização do discurso midiático entre as esferas do entretenimento, da publicidade e da informação, o que é bastante atual e evidente na comunicação persuasiva das publicidades é a sua busca pela interatividade 4 . A ideia de buscar o investimento do consumidor na marca, seja por meio de aplicativos, geração de conteúdos em redes sociais ou produção de vídeos, aponta formas de interação mais intensa com o público, de modo a estimular relações com o produto ou marca.

Compreendendo que o esporte pode assumir a condição de um conteúdo de entretenimento (mercadoria) explorado pela mídia e que se funde com os interesses comerciais da publicidade, e propicia a interatividade ao público por meio dos diferentes canais, especialmente internet, pensamos ser possível denominarmos este novo recurso utilizado no processo de midiatização do esporte de "esporte-publicitário-interativo". O esporte-publicitáriointerativo, assim, é uma nova forma de expressão do conteúdo esportivo da mídia, que entrelaça a lógica comercial da publicidade com o entretenimento, na produção de um formato híbrido que integra linguagens e códigos, e incentiva a participação/interação do receptor. Nesta fusão, por vezes, os propósitos mercadológicos ficam obscurecidos pela diversão proporcionada e pela utilização dos diferentes recursos tecnológicos, o que pode contribuir para a integração ingênua aos produtos e conteúdos da publicidade.

Outra característica do anúncio publicitário televisivo da Sadia, observada também em outras publicidades, que funciona para ancoragem de valores e representações à narrativa,

4 Ao referir-se ao conceito de interatividade, Belloni (2001, p. 58) destaca o cuidado de não o confundirmos com interação. "É fundamental esclarecer com precisão a diferença entre o conceito sociológico de interação - ação recíproca entre dois ou mais atores onde ocorre intersubjetividade, isto é, encontro de dois sujeitos que pode ser direta ou indireta [...]; e a interatividade, termo que vem sendo usado indistintamente como dois significados diferentes em geral confundidos: de um lado a potencialidade técnica oferecida por determinado meio 
refere-se ao fato de não anunciar nenhum produto específico da empresa, mas sim sua marca (publicidade institucional) como estratégia de registro e memória que abarca mais possibilidades de exploração e extensão. Tal fato pode ser compreendido por dois aspectos que impulsionam as novas estratégias publicitárias, explicadas por Covaleski (2010). Por um lado a saturação do mercado, observada pela enxurrada de produtos semelhantes, que levou os publicitários a estabelecerem uma nova relação, não mais entre marcas e produtos, mas agora entre marcas e conteúdo de interesse do consumidor, neste caso a Copa do Mundo de Futebol - FIFA. Por outro, dentro da concepção de narrativas publicitárias transmídias, a intenção volta-se para a associação da marca com um contexto/índice, uma história que começa a ser contada em uma mídia matriz, geralmente a TV, por ser uma mídia de massa, despertando o interesse dos consumidores a se envolverem com a história por meio dos vários suportes (onde então se apresentam os produtos de forma menos explícita), e por meio dos personagens, como as crianças dos anúncios da Sadia ou a mascote da marca, no caso o peru (ave) da Sadia.

Sampaio (2000) afirma que a imagem da criança é explorada não apenas por produtos voltados ao seu consumo, mas também por promover a identificação com outras crianças, para o rejuvenescimento de marcas e, sobretudo, pelo apelo emocional e sensibilização que causa nos consumidores, gerando empatia com anunciantes e favorecendo a aprovação de comerciais. Assim, utilizam-se crianças para vender carros, celulares, instituições bancárias, alimentos diversos. As comunicações publicitárias, a exemplo da campanha observada, parecem autorizar/legitimar a exposição e exploração da imagem infantil na mídia, afinal, elas são as torcedoras (consumidoras?) protagonistas da seleção e para quem se deve jogar (comprar?).

Vídeos e imagens das crianças participando das narrativas e expressões construídas pelas marcas são publicados e compartilhados nas redes sociais, seguidos das hashtags, exatamente no momento em que se discute a proteção dos direitos das crianças frente à mídia/ publicidade, tornando-se urgentes algumas indagações: será que as crianças desejam esta exposição? Ou esta exposição reflete os desejos dos pais/adultos projetados nas crianças? 0 que significa jogar para a criança? E comprar?

Ao escrever sobre as marcas comerciais, Jenkins (2009) explica que o mercado publicitário tem buscado o impacto emocional para criar conexão com os consumidores; desta forma, o apelo infantil e associação com temas e conteúdos de interesse coletivo (como esporte, ou futebol na Copa) são estratégias frequentemente adotadas. A extensão da marca é explicada a partir das ideias de Steven J. Heyer, presidente da Coca-Cola, que afirma ser uma lógica de exploração de múltiplos canais de contato com os consumidores, que almeja conexão por meio do impacto emocional e exploração de um determinado conteúdo para associá-lo repetidamente à marca. Jenkins (2009) refere-se ao surgimento das lovemarks, que, por meio do amor e respeito dos consumidores, gerarão um "capital emocional", por meio do investimento do consumidor na marca, e não simplesmente a sua exposição a ela.

Numa perspectiva interativa, os consumidores, particularmente as crianças, neste novo cenário da publicidade que observamos na campanha da Sadia, não apenas assistem os meios de comunicação; elas são convidadas a participar/compartilhar o que assistem - seja através da criação e veiculação de vídeos nos sites e redes sociais, postando o slogan ou hashtag da campanha na produção e recomendação de produtos, ou ainda utilizando os aplicativos disponibilizados. 
Nesta perspectiva, a TV aberta é utilizada como âncora de uma publicidade baseada na oferta de experiências e orientada ao acesso de conteúdos que propiciem ligações afetivas com a marca. $O$ objetivo, então, não se restringe apenas a vender mercadorias, mas também a buscar o engajamento do consumidor, de modo a criar vínculos. Como explica Castro (2012), a ambição de mobilizar os consumidores como parceiros e fãs das suas marcas encontra-se explícita, em maior ou menor grau, na maioria das campanhas publicitárias atuais, tornando-se necessárias a reflexão e a problematização desta participação dita "espontânea", tendo em vista os predicativos semiformativos da Indústria Cultural.

\section{REFLEXÕES FINAIS: A CRÍTICA PERMANENTE DA/NA CULTURA ESPORTIVA}

No que tange à apropriação do conteúdo esportivo pela mídia/TIC, a exemplo da campanha da Sadia, identificamos o surgimento de um novo recurso/formato do chamado esporte-da-mídia, derivado da progressiva hibridização entre o discurso publicitário e 0 entretenimento, que explora narrativas transmidiáticas do esporte e propõe a interatividade como um novo serviço ao cliente: o "esporte-publicitário-interativo". Escapando aos reclames tradicionais, este recurso híbrido camufla os propósitos comerciais ao oferecer diferentes experiências com o conteúdo esportivo, travestido de entretenimento, e convida os consumidores-crianças a participar nas diferentes plataformas.

Neste contexto é importante refletirmos sobre quais os interesses da publicidade em investir na imagem e utilização das crianças como garotos-propaganda, e também de utilizar o esporte como conteúdo de interesse? Afinal não são escolhas aleatórias, cumprem funções comerciais. Os estudos sobre a publicidade e a infância apontam que este grupo geracional detém grande poder de interferência na escolha de produtos/consumo no ambiente familiar (GIACOMINI FILHO, 1998; RABELO; CARDOSO, 2013), com destaque para os produtos alimentícios, como é o caso da Sadia; Rabelo e Cardoso (2013) afirmam que $92 \%$ das decisões de compras familiares, deste tipo de produtos, são influenciadas pelas crianças. Ainda, observa-se nas novas gerações a possibilidade cativa de encontrar os possíveis consumidores produtores e replicadores de informações nas múltiplas plataformas de mídia, em suas condições de nativos digitais. Familiarizadas com as linguagens e recursos da sociedade digital, as crianças tornam-se hábeis navegadoras deste universo, portanto, público-alvo capaz de investir e engajar-se nas formas interativas e colaborativas de replicar os conteúdos comerciais da empresa, além de interferir no consumo doméstico.

A possibilidade de dar respostas através dos meios técnicos interativos não significa 0 estabelecimento de uma interação recíproca com o emissor, como sujeito da comunicação, em um ambiente horizontal de negociações de sentidos. A verticalidade das ações comunicativas no ambiente digital interativo, operada pelas grandes corporações e produtoras de conteúdos da Indústria Cultural, é uma característica que, mesmo diante da interatividade proposta, continua a estabelecer relações desiguais e de colonização, particularmente no caso infantil. A coerção da emissão, que Duarte (2014) nos elucida fazer parte do processo de operacionalização dos intuitos da "Indústria Cultural 2.0", em que todos precisam dar respostas e estar conectados full time, determina como importante, em termos econômicos, o simples uso das ferramentas disponíveis, e não o conteúdo de sua participação, tendo em vista o potencial publicitário envolvido na integração aos meios e recursos. 
A prevalência das lógicas comerciais do esporte-da-mídia vistas por meio do discurso publicitário no processo de espetacularização de eventos esportivos (Copa FIFA) pode contribuir para a redução das possibilidades interpretativas da cultura esportiva e da sociedade, e sua penetração inconsciente/subliminar camuflada de entretenimento (diversão), precisando se tornar objeto consciente de reflexão-ação nas práticas pedagógicas comprometidas com 0 esclarecimento e emancipação. Isto porque a história narrada por meio do esporte-publicitáriointerativo esconde os propósitos persuasivos das propagandas e desperta 0 interesse das crianças-receptoras (agora, também emissores) em se envolverem com a história-narrativa que diverte. Estrategicamente democráticos, os novos recursos digitais que propiciam a interatividade menos se importam com o conteúdo do que é compartilhado, e mais em aumentar o potencial publicitário, ou seja, o valor da empresa. Assim, um evento como a Copa do Mundo da FIFA precisa das audiências e integrações transmidiáticas para que sua "marca" continue a render, e seus patrocinadores têm investido milhões para que as crianças também sejam público cativo.

Em seu estudo sobre as representações do ser brasileiro nas publicidades da Copa do Mundo de Futebol da FIFA, Gastaldo (2002) também identificou a utilização da imagem infantil em anúncios televisivos como uma estratégia do discurso comercial, que promovia três representações do ser criança: a criança-filho, a criança-craque e a criança-esperança. Em nosso estudo, além destas prerrogativas constatadas por Gastaldo (2002), também percebemos nas imagens da campanha "Joga pra Mim", da Sadia, a construção de outras duas representações da infância: a criança-esperta (autônoma, independente da família, que se relaciona com habilidade e desenvoltura, com destaque nos usos das tecnologias e mídia) e a criança-torcedora (fã de futebol, no caso a Copa do Mundo de Futebol, que apesar de não praticar ou jogar futebol relaciona-se de modo ativo no consumo do evento). O protagonismo infantil nas publicidades analisadas assume o papel de personagens transmidiáticos, garotos(as)-propaganda, que fazem elo entre o plano da narrativa e o plano real, sendo que a exaltação de seus traços identitários revela um pouco do público-alvo que seja atingir e as representações que ajuda a disseminar.

Se é possível perceber que a Indústria Cultural, no âmbito da cultura de convergência, parece ampliar suas possibilidades de sedução, conquista e fidelização dos seus consumidores, é relevante destacar, também, que a convergência midiática e a cultura colaborativa também abrem possibilidades de resistência (DUARTE, 2014). De fato, os conteúdos produzidos e compartilhados pelos usuários, especialmente nas redes sociais, nos mostram que é possível construir contranarrativas à história "oficial", de modo a estabelecer ruídos 5 e oposições à comunicação persuasiva, isto é, brechas para pensar o contraditório, as limitações e manipulações.

Nesse sentido, no ensaio Educação para quê?, Adorno nos convida a pensar nas possibilidades da experiência formativa como um processo autorreflexivo, do sujeito tomado pela heteronomia das condições objetivas que operam a dominação, inclusive tecendo observações para a educação das crianças, que deveria fortalecer a resistência, desde a primeira infância, para que "[...] o processo de conscientização se desenvolva paralelamente

5 Outros exemplos de interferência na narrativa publicitária, durante a Copa de 2014, particularmente nos anúncios da campanha da CocaCola, denominada A Copa DE Todo Mundo, foram estudados por Pereira (2014), ao abordar a cultura jamming, um movimento de resistência, e suas ações subversivas de desorganizar a mensagem publicitária, que virou a Copa DESPEJA Todo Mundo, ligado às manifestações populares de protesto à realização do evento no Brasil. 
ao processo de promoção da espontaneidade." (ADORNO, 1995, p. 147). Tarefa que no âmbito das relações entre a educação e comunicação são pensadas e organizadas pelo campo de estudo e intervenção da mídia-educação (física) ${ }^{6}$, que tem como propósito a formação de sujeitos esclarecidos diante da mídia/TIC.

Assim, compreender o discurso publicitário no esporte-da-mídia e suas implicações para cultura esportiva das crianças nos leva a destacar o lócus da mediação, como uma possibilidade de, pelo esclarecimento, criar as resistência e provocar as contradições necessárias à ressignificação da mídia/TIC que pode conduzir à semicultura/semiformação esportiva (PIRES, 2002). Para tanto, cumpre à educação (e à Educação Física) preservar/ garantir o espaço da dimensão crítica, considerando a publicização como um elemento importante do discurso midiático contemporâneo. Afinal, cabe destacar (e não se esquecer!) que quando o esporte-publicitário-interativo vende sonhos e desejos, "[...] a fábrica de sonhos não fabrica os sonhos dos clientes, mas dissemina na população o sonho dos fornecedores" (ADORNO, 2003, p. 91).

\section{REFERÊNCIAS}

ADORNO, Theodor W.; HORKHEIMER, Max. Dialética do esclarecimento. Rio de Janeiro: Zahar, 1985.

ADORNO, Theodor W. Educação e emancipação. Rio de Janeiro: Paz e Terra, 1995.

ADORNO, Theodor W. O esquema da cultura de massas. In: RIBEIRO, António Sousa. (Org). Sobre a indústria da cultura. Coimbra: Angelus Novus, 2003, p. 57-95.

BAKHTIN, Mikhail M. Estética da criação verbal. 2. ed. São Paulo: Martins Fontes, 1997.

BELLONI, Maria Luiza. Crianças e mídias no Brasil: cenários de mudança. Campinas: Papirus, 2010.

BELLONI, Maria Luiza. O que é mídia educação. Campinas: Autores Associados, 2001.

BELLONI, Maria Luiza. O lazer espetacularizado: cultura do narcisismo e indústria cultural. Motrivivência, v.12, n. 17, p.85-103, set. 2001.

BETTI, Mauro. Janela de vidro: esporte, televisão e educação física. Campinas: Papirus, 1998.

BRACHT, Valter. Sociologia crítica do esporte: uma introdução. 2.ed. rev. ljuí: Unijuí, 2003.

BUCKINGHAM, David. Repensando a criança-consumidora: novas práticas, novos paradigmas. Comunicação, Mídia e Consumo,v.9, n.25, p.43-72, 2012.

CASTRO, Gisela Grangeiro da Silva. Entretenimento, sociabilidade e consumo nas redes sociais: cativando o consumidor-fã. In: ROCHA, Rose de Melo; CASAQUI, Vander (Orgs.). Estéticas midiáticas e narrativas do consumo. Porto Alegre: Sulina, 2012.p.187-206.

CORSARO, Willian A. A reprodução interpretativa no brincar de "faz-de-conta" das crianças. Educação, Sociedade e Culturas, n.1, p.113-134, 2002.

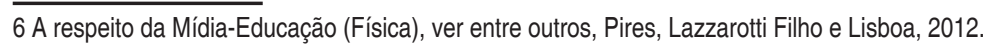


COVALESKI, Rogério. O processo de hibridização da narrativa publicitária. Comunicación, v.1, n.10, p.52-62, 2012.

COVALESKI, Rogério. Publicidade híbrida. Curitiba: Maxi, 2010.

DUARTE, Rodrigo. Indústria cultural 2.0. In: BRAIDA, Celso; DRUCKER, Claudia; BARBOZA, Jair (Orgs.). Café Filosófico: estética e filosofia da arte. Florianópolis: Ed. UFSC, 2014. p. 166199.

DEBORD, Guy. A sociedade do espetáculo. Rio de Janeiro: Contraponto, 1997.

FAUSTO NETO, Antonio. O agendamento do esporte: uma breve revisão teórica e conceitual. Verso \& Reverso, v. 16, n. 34, p. 9-17, jan./jun. 2002.

FERRÉS, Joan. Televisão e educação. Porto Alegre: Artes Médicas, 1996.

FERRÉS, Joan. Televisão subliminar: socializando através de comunicações despercebidas. Porto Alegre: Artmed, 1998.

GASTALDO, Edison. Pátria, chuteiras e propaganda. São Paulo: Annablume, 2002.

GIACOMINI FILHO, Gino. A criança no marketing e na comunicação publicitária. In: PACHECO, Elza Dias Pacheco (Org.). Televisão, criança, imaginário e educação. Campinas: Papirus, 1998. p.135-150.

JENKINS, Henry. Cultura da convergência. São Paulo: Aleph, 2009.

KEHL, Maria Rita. O espetáculo como meio de subjetivação. In: BUCCI, Eugênio; KEHL, Maria Rita (Orgs.). Videologias: ensaios sobre televisão. São Paulo: Boitempo, 2004. p.43-62.

LISBOA, Mariana Mendonça. Representações do esporte-da-mídia na cultura lúdica de crianças. In: CONGRESSO BRASILEIRO DE CIÊNCIAS DO ESPORTE, 15; CONGRESSO INTERNACIONAL DE CIÊNCIAS DO ESPORTE, 2, 2007. Anais... Recife: CBCE, 2007. p.110.

MORLEY, David. The "Nationwide" Audience. London: British Film Institute, 1980.

PASSARELLI, Brasilina; JUNQUEIRA, Antônio Hélio. Gerações interativas no Brasil: crianças e adolescentes diante das telas. São Paulo: Escola do Futuro/ USP, 2012.

PEREIRA, Rita Marisa Ribes. Infância, televisão e publicidade: metodologia de pesquisa em construção. São Paulo, Cadernos de Pesquisa, n.115, p.235-264, mar.2002.

PIRES, Giovani Lorenzi. Educação Física e o discurso midiático: abordagem críticoemancipatória. ljuí: Ed. UNIJUI, 2002.

PIRES, Giovani Lorenzi; LAZZAROTTI FILHO, Ari; LISBOA, Mariana M. Educação física, mídia e tecnologias - incursões, pesquisa e perspectivas. Kinesis, v.30, n.1, p.55-79, jan./jun. 2012.

RECUERO, Raquel. Redes sociais na internet. Porto Alegre: Sulina, 2009.

ROCHA, Maria Eduarda Mota. Consumo traz felicidade? A publicidade no centro da cultura. Comunicação, Mídia e Consumo, v. 8, n.23, p.161-179, nov. 2011. 
SAMPAIO, Inês Vitorino. Televisão, publicidade e infância. São Paulo: Annablume, 2000.

SHANK, Matthew. Sport marketing: a strategic perspective. New York: Prentice Hall, 2002.

TAMBUCCI, Pascoal Luiz. Marketing esportivo. In: YANAZE, Misturu Higuchi (Org.). Gestão de marketing e comunicação: avanços e aplicações. São Paulo: Saraiva, 2011. p.17-42. 